\title{
LOW-COST EXTRAPOLATION METHOD FOR MAXIMAL LTE RADIO BASE STATION EXPOSURE ESTIMATION: TEST AND VALIDATION
}

\author{
Leen Verloock ${ }^{1, *}$, Wout Joseph ${ }^{1}$, Azeddine Gati², Nadège Varsier², Björn Flach ${ }^{3}$, Joe Wiart ${ }^{2}$, Luc Martens ${ }^{1}$ \\ ${ }^{1}$ Department of Information Technology, Ghent University / IBBT, Gaston Crommenlaan 8, B-9050 Ghent, \\ Belgium \\ ${ }^{2}$ Orange Labs, France Télécom Division R\&D, 38-40, rue Général Leclerc 92794 Issy les Moulineaux, France \\ ${ }^{3}$ Ericsson AB, Ericsson Research, Färögatan 6, SE-16480, Stockholm
}

*Corresponding author: email: leen.verloock@ intec.UGent.be, tel: +32 (0) 933 14918, fax: +32 (0) 93314899

Received month date year, amended month date year, accepted month date year

Running title: Low-Cost LTE Extrapolation Validation.

\begin{abstract}
An experimental validation of a low-cost method for extrapolation and estimation of maximal electromagnetic-field exposure from Long Term Evolution (LTE) radio base station (RBS) installations are presented. No knowledge on downlink band occupation or service characteristics is required for the low-cost method. The method is applicable insitu. It only requires a basic spectrum analyzer with appropriate field probes without the need of expensive dedicated LTE decoders. The method is validated both in lab and in situ, for a single-input single-output (SISO) antenna LTE system and a $2 \times 2$ multiple-input multiple-output (MIMO) system, with low deviations in comparison with signals measured using dedicated LTE decoders.
\end{abstract}

\section{INTRODUCTION}

Long Term Evolution (LTE) is a new mobile communication technology marketed as the fourth generation (4G) of radio technologies (1). First deployments in Scandinavia, for example, started in 2009 and in several countries LTE rollouts are planned. It is needed to assess human exposure from this emerging mobile network technology (research agenda of the World Health Organization (WHO) ${ }^{(2)}$.

Generally, standards such as those from the European Committee for Electrotechnical Standardization (CENELEC) ${ }^{\text {(3) }}$ concerning in-situ measurements deal fairly with the exposure to base station antenna emissions of "regular" signals such as GSM (Global System for Mobile Communications) and UMTS (Universal Mobile Telecommunications System) and in many cases, a simple measurement of electric field strength with a basic spectrum analyzer (SA) and classical radiofrequency (RF) measurement instruments is enough to assess the exposure ${ }^{(4,5,6)}$.

The objective of this paper is to validate a low-cost extrapolation method for maximal LTE exposure from radio base station (RBS) installations i.e., not needing specific hardware (decoders) and LTE-analysis software. Previous studies focus on momentary field exposure or propose dedicated equipment to assess maximal LTE field values. The novelty here is thus the validation of a new low-cost method to estimate maximal LTE base station exposure using a basic spectrum analyser. Appropriate settings are proposed ${ }^{(7)}$ and the method can be used for single-input singleoutput (SISO) and multiple-input multiple-output (MIMO) LTE systems.

This method enables authorities, network operators, and researchers to assess in-situ maximal LTE exposure from RBS installations in order to check compliance with international guidelines such as those of the International Commission on Non-ionizing Radiation Protection (ICNIRP) ${ }^{(8)}$. The validation of the proposed method is performed in lab and in situ in three countries namely, Belgium, France, and Sweden, for a SISO LTE system and a 2x2 MIMO system, with dedicated LTE equipment and LTE decoders. Only, the LTE frequency division duplexing (FDD) mode is considered for all measurements.

\section{METHOD AND VALIDATION MEASUREMENTS}

The lab measurements setup in Belgium consisted of an LTE signal generator (type SMBV 100A, Rohde \& Schwarz, Zaventem, Belgium), a spectrum analyzer 
(SA) (frequency range of $9 \mathrm{kHz}-6 \mathrm{GHz}$ ) (type FSL6 Rohde and Schwarz) in combination with tri-axial Rohde and Schwarz TS-EMF Isotropic Antennas (dynamic range of $1 \mathrm{mV} / \mathrm{m}-100 \mathrm{~V} / \mathrm{m}$ for a frequency range of $80 \mathrm{MHz}-3 \mathrm{GHz}$ ) to analyze the LTE signal, and an LTE decoder with Romes software (type TSMW, Rohde and Schwarz, sensitivity: $-123 \mathrm{dBm}$ ) for validation purposes. It scans the different present cell IDs and measures common channel powers. This is a cable connected setup i.e., all equipment is connected using cables and no influences of environment (such as fading, etc.) are present. For the lab tests, 9 different LTE signals with different traffic loads $(0,25,50,75$, $100 \%)$ were generated using the LTE generator and measurements with the LTE decoders and with the basic spectrum analyzer (proposed settings according to above) were performed.

The in-situ measurements setup consisted of a tri-axial Rohde and Schwarz TS-EMF isotropic antenna in combination with a spectrum analyzer (type FSL6, frequency range of $9 \mathrm{kHz}-6 \mathrm{GHz}$ ). Validations were performed using a Rohde \& Schwarz FSH-4 spectrum analyzer with an LTE decoder option. In France, the insitu measurements setup consisted of a tri-axial isotropic antenna (INSITE Free system, Satimo) in combination with an Agilent MXA spectrum analyzer. For the in-situ validation of the method, 15 measurements were performed at a height of $1.5 \mathrm{~m}$ near an LTE base station in Haasrode (suburban environment), Belgium (2X2 MIMO, frequency 1814.9 MHz, channel bandwidth $10 \mathrm{MHz}$ ). The method was also validated in France: 3 outdoor measurements were performed at a height of $1.7 \mathrm{~m}$ at France Telecom trial sites based in Bagneux, Cachan and Arcueil (suburban environment), France (SISO, frequency $2680 \mathrm{MHz}$, channel bandwidth $10 \mathrm{MHz}$ ).

In-situ measurements were also conducted on two $2 \times 2$ MIMO LTE radio base station sites at 7 different locations in Stockholm, Sweden. The setup consisted of a tri-axial isotropic antenna (TSEMF-B1) in combination with a Rohde and Schwarz FSH-4 spectrum analyzer with an LTE decoder option. The 7 measurements were performed near 2 LTE base stations (Antenna configuration: $2 \times 2$ MIMO single antenna with two polarizations, frequency $2660 \mathrm{MHz}$, channel bandwidth $20 \mathrm{MHz}$ ).

The measurement uncertainty is $\pm 3 \mathrm{~dB}$ for the considered SA setup ${ }^{(3)}$. This uncertainty represents the expanded uncertainty evaluated using a confidence interval of $95 \%$ (thus estimated at the level of twice the standard deviation, corresponding, in the case of a normal distribution, to a confidence level of $95 \%$ ).

With dedicated LTE decoders, the LTE reference signal (RS) can be measured and extrapolated ${ }^{(9)}$. Using a basic spectrum analyzer, the power of the RS cannot be detected since RSs generally have a too low power level. To overcome these LTE power issues for our exposure assessment method that must not require previous knowledge on band occupation or service characteristics, we focused on the physical broadcast channel $(\mathrm{PBCH})$ instead of the RS. The PBCH is transmitted with same characteristics regardless of configuration or service bandwidth and always spans about $1 \mathrm{MHz}$ over the emission frequency. The $\mathrm{PBCH}$ power is relatively strong ${ }^{(1)}$, and thus can be measured using a basic spectrum analyzer ${ }^{(9)}$.

The correct settings of the spectrum analyzer are extremely important: only with appropriate settings can the $\mathrm{PBCH}$ power be measured correctly. We propose the following settings partly described in Feliachi et al., $2011^{(7)}$ and here optimized. The centre frequency of the spectrum analyzer must be equal to the centre frequency of the LTE signal. The frequency span has to be set to zero (scope mode) in order to measure the received time signal at the downlink emission frequency. A resolution bandwidth (RBW) of $1 \mathrm{MHz}$ is used to integrate the signal over the $\mathrm{PBCH}$ spectral spread. The sweep time (SWT) has to be (about) equal to the multiplication of the number of display points of the SA and the symbol duration of $66.7 \mu$ s, in order to obtain an integration time close to the symbol duration of each pixel on the screen of the SA. This results, for our case, in a sweep of SWT $=70 \mathrm{~ms}$ over 1000 measurement points. Moreover, a root-mean-square (RMS) detector combined with a maximum hold time of $20 \mathrm{~s}$ can be used to measure the peak power, which will correspond to the estimated PBCH power Plow-cost (a maximum-hold measurement with a SA is a narrowband measurement of a signal with the maximum-hold setting kept during a time interval until the SA reading stabilizes) (denoted here as "RMS" method)

Figure 1 (a) shows an SA measurement of one LTE frame in zero span mode around the center frequency for only one sweep. Different control signals are indicated. Figure 1 (b) shows the corresponding timetable for that frame. One frame consists of 10 subframes and only in subframe 1 the $\mathrm{PBCH}$ is transmitted. The $\mathrm{PBCH}$ is transmitted with relatively strong power, so it can be measured using the proposed SA settings. Figure 1 (c) shows the power of the LTE channel as a function of the frequency (no traffic), measured with the SA (SWT $20 \mathrm{sec}$, RMS detector, hold time $0 \mathrm{sec}$, RBW $1 \mathrm{MHz}$, Span $30 \mathrm{MHz}$ ) Again the $\mathrm{PBCH}$ is indicated.

Figure 1. (a) SA measurement of 1 LTE frame in zero span mode (no maximum hold) around the center frequency using appropriate settings for an LTE signal without data traffic, (b) corresponding timetable for that frame, and (c) frequency domain measurement of LTE signal with indication of the PBCH (no traffic). (P-SYNC = primary synchronization signal, S-SYNC $=$ secondary 
synchronization signal, $\mathrm{PBCH}=$ physical broadcast channel).

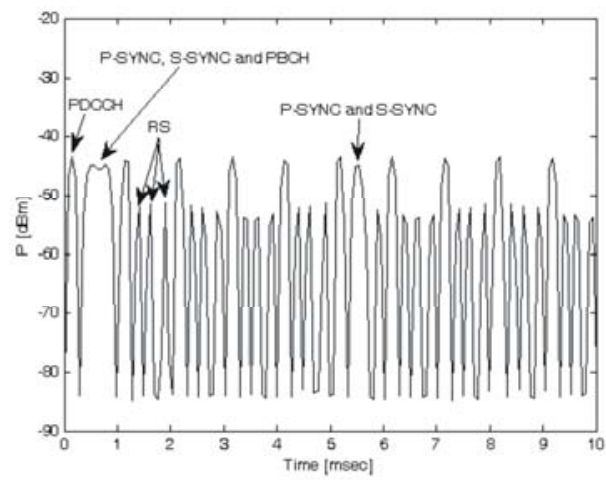

(a)

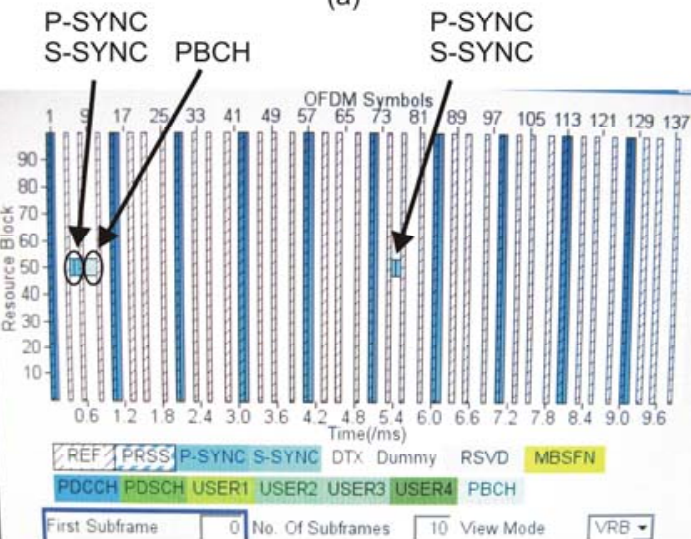

(b)

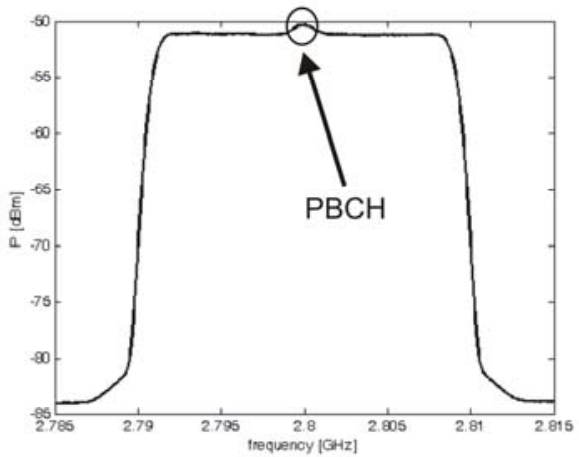

(c)

Once the $\mathrm{PBCH}$ power is measured with these correct SA settings, the following method is proposed to estimate the maximal exposure level ( $\left.\mathrm{E}_{\max }\right)$ of the LTE signal at a measurement location (the extrapolation method is valid for both SISO and MIMO):
$E_{\max }=\sqrt{n_{P B C H}} \cdot E_{P B C H} \quad(\mathrm{~V} / \mathrm{m})$

With Еввсн denoting the measured electric field value of the $\mathrm{PBCH}$ signal and $\mathrm{nPBCH}$ denoting the ratio of the maximal total output power at the base station to the power of the $\mathrm{PBCH}$ signal at the base station. provided by the network operator or can be calculated theoretically $(\mathrm{nPBCH}=10 \log (\mathrm{Ns})-10 \log (72)(\mathrm{dB})$, where $\mathrm{Ns}=$ number of subcarriers), assuming that the power of the PBCH subcarriers are at the same power level as the other subcarriers.

Table 1 summarizes the "in-lab" comparison of the true PBCH powers of the LTE signal Ptrue (measured with the LTE decoders) and the LTE powers Plow-cost measured with the proposed method for different scenarios (i.e., different LTE signals and traffic loads). Deviations between true powers and measured powers are in general below $1 \mathrm{~dB}(0.9 \mathrm{~dB}$ on average $)$ and maximally $1.8 \mathrm{~dB}$, which is well below the uncertainty of $\pm 3 \mathrm{~dB}$. These deviations are thus obtained for different traffic loads.

Table 1 summarizes also the 15 "in-situ" measurements performed in Belgium and those performed in Cachan, France and the comparison between the true LTE powers Ptrue (measured with the LTE decoder) and the LTE powers measured with the proposed method (Plowcost). Compared to the lab tests where the generator is directly connected to the measurement instrument, the LTE signal is transmitted over the air during the in-situ field tests and also variations of environment (e.g., traffic, SA and decoder measurements at different time instances, not exact at same location, etc.) will influence the comparison. Deviations between true powers and measured powers are in general below and around $1 \mathrm{~dB}$ (Table $1,1.1 \mathrm{~dB}$ on average) and maximally $2.9 \mathrm{~dB}$ (for lowest powers, near sensitivity of the system), which is again below the uncertainty of $\pm 3 \mathrm{~dB}$.

Table 2 summarizes the 7 in-situ measurements performed in Sweden on 2x2 MIMO LTE base station sites. Time variations of the environment may have influenced the results (in situ). Deviations between extrapolated maximum powers (from the decoder RS signal measurements) and the extrapolated maximum powers (from the SA PBCH signal measurements) are generally less than $2 \mathrm{~dB}$ and maximally $4.2 \mathrm{~dB}$, which is acceptable for in-situ measurements.

Figure 2 shows the cumulative distribution function (CDF) of the deviations for all the measurements. The $95^{\text {th }}$ percentile is $3 \mathrm{~dB}$, which corresponds to the measurement uncertainty of the measurement setup.

Figure 2. CDF of all deviations. 


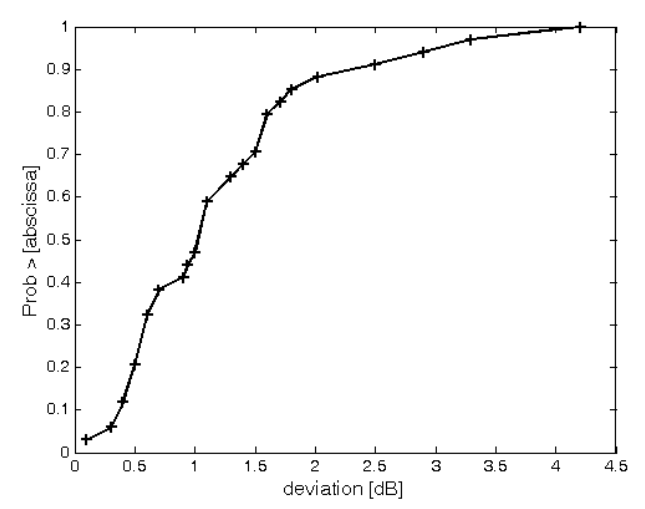

CONCLUSION

The proposed low-cost measurement method using the physical broadcast channel $(\mathrm{PBCH})$ of the LTE signal with a basic spectrum analyzer, gives accurate results, both in-lab and in-situ. MIMO seems to have no major impact on the extrapolation of the results. With the appropriate spectrum analyzer settings, accurate results are obtained and extrapolation to estimate maximal LTE exposure can be performed, without the need of expensive dedicated LTE decoders. Authorities, researchers, and mobile operators can use this method for in-situ compliance testing of maximal LTE exposure. Future research will be the application of the proposed method to assess maximal LTE exposure, once LTE networks are deployed.

\section{REFERENCES}

1. 3rd Generation Partnership Project (3GPP). 2011. Technical Specification Group Radio Access Network; Evolved Universal Terrestrial Radio Access (E-UTRA); Physical Channels and Modulation, release 10, 3GPP TS 36.211 v10.1.0. Sophia-Antipolis Cedex France: 3GPP.

2. World Health Organization (WHO). 2010. WHO Research Agenda Geneva, Switzerland. Available at whqlibdoc.who.int/publications/2010/9789241599948_eng .pdf (Last accessed 9 September 2011).

3. CENELEC European Committee for Electrotechnical Standardization. 2008. TC 106x WG1 EN 50492 in situ. Basic standard for the in-situ measurement of electromagnetic field strength related to human exposure in the vicinity of base stations. Avenue Marnix Brussels Belgium: CENELEC.

4. Kim BC, Choi H-D, Park S-O. 2008. Methods of evaluating human exposure to electromagnetic fields radiated from operating base stations in Korea. Bioelectromagnetics 29(7):579-582.

5. Joseph W, Verloock L, Goeminne F, Vermeeren G, Martens L. 2010. Assessment of general public exposure to LTE and RF sources present in an urban environment. Bioelectromagnetics 31(7):576-579.

6. Joseph W, Verloock L, Goeminne F, Vermeeren G, Martens L. 2012. Assessment of RF exposures from emerging wireless communication technologies in different environments. Health Phys 102(2): 161-72, DOI: 10.1097/HP.0b013e31822f8e39

7. Feliachi R, Gati A, Wiart J. 2011. Methods for Measuring In-Situ Exposure Induced by Non-Regular Signals like WLAN and LTE, Proceedings on the fifth European conference on Antennas and Propagation (EuCAP), 25932595 .

8. International Commission on Non-Ionizing Radiation Protection (ICNIRP). 1998. Guidelines for limiting exposure to time-varying electric, magnetic, and electromagnetic fields (up $300 \mathrm{GHz}$ ). Health Phys 74(4): 494-522.

9. Joseph W, Verloock L, Goeminne F, Vermeeren G, Martens L. 2012. In-situ LTE exposure of general public: characterization and extrapolation. Bioelectromagnetics 33(6): 466-475. 


\section{SHORT TITLE}

Table 1. Measurement results for the $\mathrm{PBCH}$ signal for different test scenarios in lab and in situ. Deviations between the PBCH power measured with the LTE decoder and the $\mathrm{PBCH}$ power measured with the $\mathrm{SA}$ are provided.

\begin{tabular}{|c|c|c|c|c|c|}
\hline $\begin{array}{l}\text { Environm } \\
\text { ent }\end{array}$ & $\begin{array}{l}\text { No. } \\
\text { meas }\end{array}$ & $\begin{array}{c}\text { Description } \\
\text { (scenario/location) }\end{array}$ & $\begin{array}{c}\text { Ptrue } \\
(\mathrm{PBCH}) \\
\text { decoder } \\
(\mathrm{dBm})\end{array}$ & $\begin{array}{c}\text { Plow-cost } \\
\text { (PBCH) } \\
\text { SA } \\
(\mathrm{dBm})\end{array}$ & $\begin{array}{l}\text { Deviation } \\
\quad(\mathrm{dB})\end{array}$ \\
\hline \multirow[t]{16}{*}{$\mathrm{Lab}$} & 1 & Dummy data & -43.66 & -42.63 & 1.0 \\
\hline & 2 & No Data & -43.66 & -43.06 & 0.6 \\
\hline & \multirow[t]{2}{*}{3} & Traffic in first 25 & & & \\
\hline & & RB of subframe 0 & -43.51 & -42.78 & 0.7 \\
\hline & \multirow[t]{2}{*}{4} & Traffic in first 25 & & & \\
\hline & & RB of all subframes & -43.36 & -42.72 & 0.6 \\
\hline & \multirow[t]{2}{*}{5} & Traffic in first 50 & & & \\
\hline & & RB of subframe 0 & -43.48 & -42.85 & 0.6 \\
\hline & \multirow[t]{2}{*}{6} & Traffic in first 50 & & & \\
\hline & & RB of all subframes & -43.46 & -42.83 & 0.6 \\
\hline & \multirow[t]{2}{*}{7} & Traffic in first 75 & & & \\
\hline & & $\mathrm{RB}$ of subframe 0 & -43.36 & -42.23 & 1.1 \\
\hline & \multirow{4}{*}{9} & Traffic in first 75 & & & \\
\hline & & RB of all subframes & -43.59 & -41.75 & 1.8 \\
\hline & & Traffic in all 100 & & & \\
\hline & & RB of subframe 0 & -43.66 & -42.55 & 1.1 \\
\hline \multirow{26}{*}{$\begin{array}{l}\text { In-situ } \\
\text { Belgium } \\
\text { (MIMO) }\end{array}$} & 1 & LOS, $37 \mathrm{~m}$ from BS & -52.45 & -52.92 & 0.5 \\
\hline & 2 & LOS, $37 \mathrm{~m}$ from BS & -61.20 & -58.28 & 2.9 \\
\hline & 3 & LOS, $37 \mathrm{~m}$ from BS & -51.74 & -51.20 & 0.5 \\
\hline & \multirow[t]{2}{*}{4} & LOS, $128 \mathrm{~m}$ from & & & \\
\hline & & BS & -57.53 & -57.46 & 0.1 \\
\hline & \multirow[t]{2}{*}{5} & LOS, $128 \mathrm{~m}$ from & & & \\
\hline & & BS & -59.99 & -59.55 & 0.4 \\
\hline & \multirow[t]{2}{*}{6} & LOS, $128 \mathrm{~m}$ from & & & \\
\hline & & BS & -60.82 & -59.76 & 1.1 \\
\hline & \multirow[t]{2}{*}{7} & LOS, $458 \mathrm{~m}$ from & & & \\
\hline & & BS & -53.83 & -52.30 & 1.5 \\
\hline & \multirow[t]{2}{*}{8} & LOS, $458 \mathrm{~m}$ from & & & \\
\hline & & BS & -56.06 & -53.58 & 2.5 \\
\hline & \multirow[t]{2}{*}{9} & LOS, $458 \mathrm{~m}$ from & & & \\
\hline & & BS & -51.10 & -50.43 & 0.7 \\
\hline & \multirow[t]{2}{*}{10} & LOS, $548 \mathrm{~m}$ from & & & \\
\hline & & BS & -53.85 & -54.27 & 0.4 \\
\hline & \multirow[t]{2}{*}{11} & LOS, $548 \mathrm{~m}$ from & & & \\
\hline & & BS & -50.88 & -49.78 & 1.1 \\
\hline & \multirow[t]{2}{*}{12} & LOS, $548 \mathrm{~m}$ from & & & \\
\hline & & BS & -50.59 & -50.28 & 0.3 \\
\hline & \multirow[t]{2}{*}{13} & LOS, $354 \mathrm{~m}$ from & & & \\
\hline & & BS & -48.42 & -46.99 & 1.4 \\
\hline & \multirow[t]{2}{*}{14} & LOS, $354 \mathrm{~m}$ from & & & \\
\hline & & BS & -46.91 & -48.22 & 1.3 \\
\hline & 15 & LOS, $354 \mathrm{~m}$ from & -41.89 & -40.56 & 1.3 \\
\hline
\end{tabular}

\begin{tabular}{|c|c|c|c|c|c|}
\hline & & BS & & & \\
\hline In-situ & 1 & Without traffic & -43.32 & -42.38 & 0.94 \\
\hline \multirow[t]{3}{*}{$\begin{array}{l}\text { France } \\
(\mathrm{SISO})\end{array}$} & 2 & $\begin{array}{l}\text { Maximum } \\
\text { simulated traffic }\end{array}$ & -43.32 & -41.3 & 2.02 \\
\hline & 3 & Simulated traffic at & & & \\
\hline & & $70 \%$ & -43.32 & -41.61 & 1.71 \\
\hline
\end{tabular}

$\mathrm{RB}=$ resource block

LOS = line of sight, $\mathrm{BS}=$ base station

Table 2. Measurement results after extrapolation to maximum exposure for different test scenarios in situ for a $2 \times 2$ MIMO LTE system. Deviations between the extrapolated maximum power (from the decoder RS signal measurements) and the extrapolated maximum power (from the SA PBCH signal measurements) are provided.

\begin{tabular}{|c|c|c|c|c|c|}
\hline $\begin{array}{l}\text { Environ } \\
\text { ment }\end{array}$ & $\begin{array}{l}\text { No. } \\
\text { meas }\end{array}$ & $\begin{array}{c}\text { Description } \\
\text { (scenario/location) }\end{array}$ & $\begin{array}{c}\mathrm{E}_{\max }(\mathrm{RS}) \\
\text { decoder } \\
(\mathrm{V} / \mathrm{m})\end{array}$ & $\begin{array}{c}\mathrm{E}_{\max } \\
(\mathrm{PBCH}) \\
\mathrm{SA}(\mathrm{V} / \mathrm{m})\end{array}$ & $\begin{array}{l}\text { Deviation } \\
\quad(\mathrm{dB})\end{array}$ \\
\hline $\begin{array}{l}\text { In-situ } \\
\text { Sweden } \\
\text { (MIMO) }\end{array}$ & $\begin{array}{l}4 \\
5 \\
6 \\
7\end{array}$ & $\begin{array}{l}\text { LOS, Site \#1, } 3 \mathrm{~m} \\
\text { from BS } \\
\text { LOS, Site \#1, } 18 \mathrm{~m} \\
\text { from BS } \\
\text { LOS, Site \#1, } 58 \mathrm{~m} \\
\text { from BS } \\
\text { LOS, Site \#1, } 105 \mathrm{~m} \\
\text { from BS } \\
\text { LOS, Site \#2, } 60 \mathrm{~m} \\
\text { from BS } \\
\text { LOS, Site \#2, } 128 \mathrm{~m} \\
\text { from BS } \\
\text { LOS, Site \#2, } 160 \mathrm{~m} \\
\text { from BS }\end{array}$ & 12.26 & 2.73 & 1.6 \\
\hline
\end{tabular}

